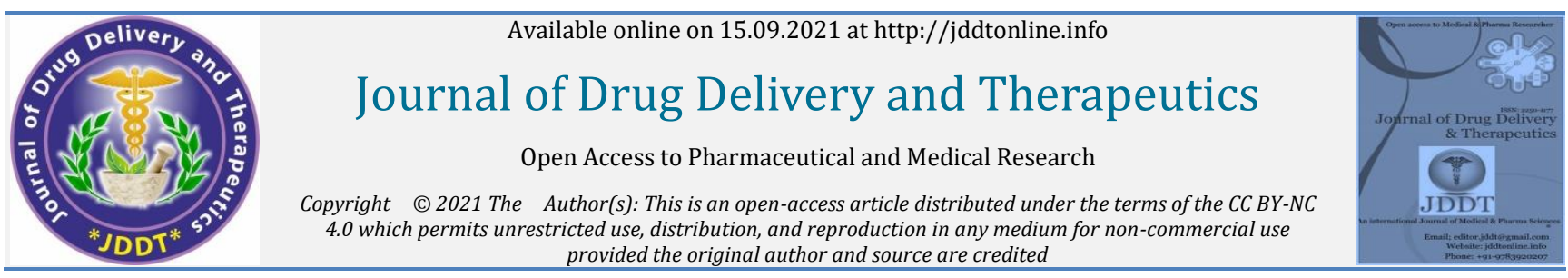

Open Access Full Text Article

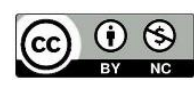

Case Study

\title{
Zidovudine Induced Pancytopenia: A Case Study
}

\author{
Santreena Simon K*, Serene Maria, Cyril Tom \\ Department of Pharmacy Practice, Shree Devi College of Pharmacy, Mangaluru, Karnataka, India
}

Article Info:

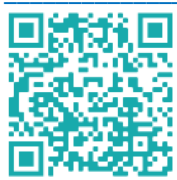

Article History:

Received 16 July 2021

Reviewed 17 August 2021

Accepted 25 August 2021

Published 15 Sep 2021

\section{Cite this article as:}

Simon K S, Maria S, Tom C, Zidovudine Induced Pancytopenia: A Case Study, Journal of Drug Delivery and Therapeutics. 2021; 11(5):8-10

DOI: http://dx.doi.org/10.22270/jddt.v11i5.4979

*Address for Correspondence:

Dr. Santreena Simon K* (Pharm.D), Department of Pharmacy Practice, Shree Devi College of Pharmacy, Mangaluru, Karnataka, India

\section{Abstract}

Zidovudine is the oldest anti-retroviral agent that is in clinical use. It's common adverse effects are headaches (42-62.5\%), nausea (46-61\%), anorexia (11-20\%), vomiting (6-25\%), anemia (1.1-29\%), granulocytopenia (1.8-37\%) and neutropenia (3\%).

This study is to increase awareness of Zidovudine induced pancytopenia. This is an observational type of case report of a 40 year old man with known complaints of HIV on anti-retroviral therapy since 8 years who came with complaints of easy fatigability since 1 year which was aggravated since 1 week, epigastric discomfort, constipation since 2 weeks, chest pain retrosternal in position which was radiating to both upper limbs, sweating, palpitations, decreased appetite since 1 week and cough with expectoration.

He was given tablet ZLN (Zidovudine $300 \mathrm{mg}$ + Lamivudine $150 \mathrm{mg}$ + Nevirapine $200 \mathrm{mg}$ ) twice daily regularly for the past 8 years. His last CD4 count was 300 cell $/ \mathrm{mm}^{3}$. He had pallor. His laboratory results were: hemoglobin $(6.6 \mathrm{~g} / \mathrm{dL})$, TLC $(2400 / \mu \mathrm{L})$, platelets $(18,000 / \mu \mathrm{L})$, neutrophil (36\%) and MCV (107.4fL). He was diagnosed with pancytopenia (dimorphic anemia + leucopenia + thrombocytopenia) and neuropathic pain.

It was confirmed to be Zidovudine induced pancytopenia by objective analysis and Naranjo score suggesting "probable" interpretation. Pancytopenia improved after withholding Zidovudine along with Oxcarbazepine. Suggestion was made to change his anti-retroviral regimen once his counts improve. Tenofovir + Lamivudine (or Emtricitabine) + Efavirenz is the preferred first line combination therapy according to latest WHO guidelines (2013 and 2015). In case Zidovudine is used in first line combination therapy (2009 WHO guidelines), physicians should monitor for its toxicity.

A clinical pharmacist can help in such situations by creating awareness among prescribers regarding latest $\mathrm{WHO}$ and other recommended guidelines, checking whether the prescriptions follow these guidelines and also by monitoring patients for toxicities.

Keywords: Zidovudine, Drug induced pancytopenia, Adverse drug reaction

\section{INTRODUCTION}

Patients infected with HIV are at increased risk of developing severe hematological complications when they are on HAART (Highly Active Anti - Retroviral Therapy). The most common cause of ART interruption was seen to be hematological ADRs in a cohort study conducted by Hossein et al in Iranian adult HIV patients in the year 2005- 2007 1. Zidovudine is the oldest anti - retroviral agent that is in clinical use 2 . It's common adverse effects are headaches $(42$ - 62.5\%), nausea (46-61\%), anorexia (11 - 20\%), vomiting (6 - 25\%), anemia (1.1 - 29\%), granulocytopenia (1.8 - 37\%) and neutropenia (3\%) 2,3 . Zidovudine induced pancytopenia has been reported as uncommon in post marketing surveillance studies. The most severe adverse effect of Zidovudine includes bone marrow suppression which causes anemia and pancytopenia. Pancytopenia is the deficiency of all three types of blood cells: RBCs, WBCs and platelets.

In a prospective study conducted on 450 HIV patients in Kasturba hospital, Manipal to characterize the pattern of ADRs due to HAART, ADRs were found to be the highest with
Zidovudine + Lamivudine + Nevirapine combination (42.3\%) and Zidovudine was reported to be causing anemia (18.3\%) and pancytopenia $(10 \%)^{4}$. Maximum ADRs to ART was seen with Zidovudine $(50 \%)$ in a two year study of 100 HIV patients in India by Sharma et al. $32.2 \%$ hematalogical ADRs were observed and anemia and leucopenia were seen in Zidovudine containing regimen in 18 patients $(20 \%)$ and in 3 patients (3.3\%) respectively5. A study was conducted by Modayil et al on 400 HIV patients in India to assess the nature, severity, predictability and preventability of ADRs and to identify risk factors for anti-retroviral therapy. 159 (52.82\%) ADRs were identified with anemia and vomiting being the most commonly observed. Risk factor for ADRs was found to be use of Zidovudine + Lamivudine with Nevirapine or Efavirenz, CD4 $<200$, female gender, tuberculosis and illiteracy. Anemia was seen in 5 patients $(55.56 \%)$ on Zidovudine + Lamivudine + Nevirapine regimen and in 1 patient $(11.11 \%)$ on Zidovudine + Lamivudine + Efavirenz regimen $\mathbf{6}$. 
This study is to increase awareness of Zidovudine induced pancytopenia and to suggest a method to prevent and manage it.

\section{CASE REPORT}

A 40 year old man with known complaints of HIV on anti-retroviral therapy since 8 years was admitted with complaints of easy fatigability since 1 year which was aggravated since 1 week, epigastric discomfort, constipation since 2 weeks, chest pain retrosternal in position which was radiating to both upper limbs, sweating, palpitations, decreased appetite since 1 week and cough with expectoration. He had pallor, facial puffiness and hypotension ( BP : Day 1- 100/60 mm Hg, Day 2 - 140/80 $\mathrm{mm} \mathrm{Hg}$, Day $3-110 / 70 \mathrm{~mm} \mathrm{Hg}$ ). He was taking tablet ZLN (Zidovudine $300 \mathrm{mg}+$ Lamivudine $150 \mathrm{mg}+$ Nevirapine 200 $\mathrm{mg}$ twice daily regularly for the past 8 years. His last CD 4 count was $300 \mathrm{cell} / \mathrm{mm}^{3}$.

His peripheral smear examination revealed pancytopenia (dimorphic anemia + leucopenia + thrombocytopenia). Hematological tests revealed anemia with hemoglobin counts of $6.6 \mathrm{~g} / \mathrm{dL}, 7.1 \mathrm{~g} / \mathrm{dL}$ and $8.2 \mathrm{~g} / \mathrm{dL}$; RBC counts of 1.62 million/cumm, 1.83 million/cumm and 2.09 million/cumm and PCV of $17.4 \%, 18.9 \%$ and $21.9 \%$ on days 1,2 and 3 respectively. Iron study, Coomb's test, vitamin B 12, folate and reticulocyte results were normal. TLC of 2400, 1800 and 2500 per $\mu \mathrm{L}$ on days 1,2 and 3 indicated leucopenia. Differential leucocyte counts results showed decreased neutrophils (Day 1 - 36\%, Day 2 - 42\%, Day $3-64 \%$ ) and increased lymphocyte count (Day 1 - 56\%, Day 2 - 52\%. Day $3-30 \%$ ) with all other leucocytes within normal range. Platelet counts of 18000,20000 and 44000 per $\mu \mathrm{L}$ on days 1 , 2 and 3 indicated thrombocytopenia. Other hematological tests showed MCV of 107.4 fL, 103.3 fL and 104.8 fL; MCH of $40.7 \mathrm{pg}, 38.8 \mathrm{pg}$ and $39.2 \mathrm{pg}$ and MCHC of $37.9 \mathrm{~g} / \mathrm{dL}, 37.6$ gdL and $37.4 \mathrm{~g} / \mathrm{dL}$ on days 1,2 and 3 respectively. Serum potassium (Day $1-3.3 \mathrm{mmol} / \mathrm{L}$, Day $3-3.2 \mathrm{mmol} / \mathrm{L}$ ) and sodium (Day 1 - $110 \mathrm{mmol} / \mathrm{L}$, Day 3 - $128 \mathrm{mmol} / \mathrm{L}$ ) levels were found to be decreased. Hemo - occult tests revealed negative results.

Final diagnosis was HIV on anti - retroviral therapy (tablet ZLN: Zidovudine + Lamivudine + Nevirapine), neuropathic pain in right half of the body and Zidovudine induced pancytopenia. Zidovudine induced pancytopenia was confirmed by objective analysis and Naranjo score of 7 suggesting "probable" interpretation [Table 1].

Table 1: Adverse Drug Reaction Probability Scale

\begin{tabular}{|c|c|c|}
\hline Question & Answer & Score \\
\hline 1. Are there previous conclusive reports on this reaction? & Yes & +1 \\
\hline 2. Did the adverse event appear after the suspected drug was administered? & Yes & +2 \\
\hline $\begin{array}{l}\text { 3. Did the adverse event improve when the drug was discontinued or a specific antagonist was } \\
\text { administered? }\end{array}$ & Yes & +1 \\
\hline 4. Did the adverse event reappear when the drug was re-administered? & Yes & +2 \\
\hline 5. Are there alternative causes that could on their own have caused the reaction? & Yes & -1 \\
\hline 6. Did the reaction reappear when a placebo was given? & Do not know & 0 \\
\hline 7. Was the drug detected in blood or other fluids in concentrations known to be toxic? & Do not know & 0 \\
\hline $\begin{array}{l}\text { 8. Was the reaction more severe when the dose was increased or less severe when the dose was } \\
\text { decreased? }\end{array}$ & Yes & +1 \\
\hline 9. Did the patient have a similar reaction to the same or similar drugs in any previous exposure? & No & 0 \\
\hline 10. Was the adverse event confirmed by any objective evidence? & Yes & +1 \\
\hline Interpretation & Probable & +7 \\
\hline
\end{tabular}

He was given Dextrose Normal Saline with vitamin B12 on day 1 for hypotension and as vitamin B12 can help in neuropathic pain and anemia. Syrup Lactulose was given for constipation for 3 days. Injection Ondansetron was given for epigastric discomfort for 3 days. Injection Pantoprazole was given for epigastric discomfort and also as a prophylactic for heartburn caused by Syrup Lactulose. Albendazole was given for anemia as helminths may cause anemia. 10 packed red cell transfusion of $350 \mathrm{~mL}$ was given for 2 days for treating severe anemia. Tablet ZLN (Zidovudine + Lamivudine + Nevirapine) and tablet Oxcarbazepine were with-held and pancytopenia improved simultaneously.

The patient's blood counts improved and were stable on day 3. He was discharged with a letter to the concerned anti - retroviral therapy centre to change his regimen once his counts improve.

\section{DISCUSSION}

The patient's peripheral smear examination report and hematological counts revealed deficiency of RBCs, WBCs and platelets which is defined as pancytopenia. We could exclude iron deficiency anemia and vitamin B 12 deficiency anemia due to normal iron study reports, vitamin B 12 , folate and reticulocyte counts. Negative hemo - occult test results ruled out blood loss from the gastrointestinal tract. Prevalence of anemia is high in patients with HIV and AIDS. But, patient is in $2^{\text {nd }}$ stage of HIV. Negative Coomb's test result ruled out auto - immune hemolytic anemia. 
Table 2

\begin{tabular}{|l|l|l|l|l|}
\hline $\begin{array}{l}\text { Hematological } \\
\text { effects }\end{array}$ & Zidovudine & Lamivudine & Nevirapine & Oxcarbazepine \\
\hline Anemia & $\begin{array}{l}1.1-29 \% \\
\text { Common }\end{array}$ & $\begin{array}{l}1-4 \% \\
\text { Post marketing } \\
\text { surveillance }\end{array}$ & $\begin{array}{l}7-7.3 \% \\
\text { Post marketing surveillance }\end{array}$ & $\begin{array}{l}\text { Aplastic anemia- Very } \\
\text { rare : Post marketing } \\
\text { surveillance }\end{array}$ \\
\hline Leucopenia & $\begin{array}{l}3 \% \\
\text { Uncommon }\end{array}$ & $\begin{array}{l}\text { No frequency } \\
\text { information }\end{array}$ & Not reported & No frequency information \\
\hline Thrombocytopenia & $\begin{array}{l}\text { Common in post } \\
\text { marketing surveillance }\end{array}$ & $\begin{array}{l}1-3 \% \\
\text { Very rare }\end{array}$ & No frequency information & Very rare \\
\hline Neutropenia & $\begin{array}{l}3 \% \\
\text { Common }\end{array}$ & $\begin{array}{l}3-8 \% \\
\text { Uncommon }\end{array}$ & $\begin{array}{l}8.9-9 \% \\
\text { Post marketing surveillance }\end{array}$ & Very rare \\
\hline Pancytopenia & $\begin{array}{l}\text { Uncommon in post } \\
\text { marketing surveillance }\end{array}$ & $\begin{array}{l}\text { No frequency } \\
\text { information }\end{array}$ & Not reported & Very rare \\
\hline
\end{tabular}

Compared to the other drugs used in the treatment, Zidovudine can be suspected to have caused pancytopenia based on the prevalence and previous literature studies [Table 2] 2,3. MCV has been proposed as a surrogate marker of adherence to Zidovudine by Joseph 0 Mugisha et al. MCV levels rise linearly for approximately the first 24 weeks of adherent treatment before reaching a steady state and change from baseline at time points after this are highly associated with HIV RNA levels. An increase by at least $8 \%$ in MCV levels after 12 weeks of initiation of combination anti-retroviral therapy correctly identifies almost $90 \%$ of virological responders and an increase of less than $8 \%$ identifies the same proportion of non-responders ${ }^{7}$. Naranjo scale of 7 suggesting probable causality interpretation also confirms Zidovudine induced pancytopenia. Furthermore, there were improvements in pancytopenia after tablet ZLN (Zidovudine + Lamivudine + Nevirapine) along with Oxcarbazepine was with-held. Use of Zidovudine should be stopped if hemoglobin level is less than $8 \mathrm{~g} / \mathrm{dL}{ }^{8}$. One limitation of the study is that rechallenge is not possible. Rechallenging a patient with a suspected agent in an attempt to confirm a diagnosis is not generally recommended because drug induced blood disorders are potentially dangerous ${ }^{9}$.

The following suggestions can be used to make changes in his therapy after his blood counts improve. Preferred treatment regimens according to WHO in WHO recommended ARV treatment schedule, 2013 and consolidated guidelines on the use of anti-retroviral drugs for treating and preventing HIV infections, June 2015 are as follows.

$\checkmark$ Preferred first line regimen: Tenofovir + Lamivudine (or Emtricitabine) + Efavirenz

$\checkmark$ Alternative regimens: If Tenofovir + Lamivudine (or Emtricitabine) + Efavirenz is contra-indicated or not available, one of the following alternative options is recommended.

$\checkmark$ Zidovudine + Lamivudine + Efavirenz

$\checkmark$ Zidovudine + Lamivudine + Nevirapine

$\checkmark$ Tenofovir + Lamivudine (or Emtricitabine ) + Nevirapine (or Dolutegravir) ${ }^{10}$

The recommended first line combination therapy for HIV infection was changed to Tenofovir + Lamivudine (or Emtricitabine) + Efavirenz from Zidovudine based combination therapy according to latest WHO guidelines of 2013 and 2015 based on efficacy and toxicity studies ${ }^{\mathbf{1 1}}$.

In case Zidovudine is used in the combination therapy to initiate treatment, physicians should monitor for hematological and other toxicities. If hemoglobin level is less than $8 \mathrm{~g} / \mathrm{dL}$, Zidovudine should be discontinued and the ART regimen should be changed 8

A case on Zidovudine induced microcytic, hypochromic anemia along with pancytopenia and hyper-pigmentation was reported in Andhra Pradesh by M. Yugander Reddy et al in which tablet ZLN (Zidovudine + Lamivudine + Nevirapine) given for 5 years was replaced with TEL (Tenofovir Disoproxil Fumarate + Efavirenz + Lamivudine) ${ }^{\mathbf{1 2}}$.

\section{CONCLUSION}

Drug induced disorders like this can be prevented to some extent if the physicians follow WHO's or other latest recommended prescribing guidelines. A clinical pharmacist can help in such situations by checking whether the prescriptions are according to WHO's or other latest recommended protocols and guidelines, conducting awareness programmes about it for physicians and monitoring patients for toxicities.

\section{REFERENCES}

1) Khalili H, Dashti-Khavidaki S, Mohraz M, Etghani A, Almasi F. Antiretroviral induced adverse drug reactions in Iranian human immunodeficiency virus positive patients. Pharmaco- epidemiology and drug safety. 2009 Sep; 18(9):848-57. https://doi.org/10.1002/pds.1793

2) https://pdf.usaid.gov/pdf_docs/Pnacj572.pdf

3) http://sideeffects.embl.de/drugs/5726/

4)http://shodhganga.inflibnet.ac.in/bitstream/10603/13064/12/12_chapter 2.pdf.pdf

5) Sharma A, Vora R, Modi M, Sharma A, Marfatia Y. Adverse effects of antiretroviral treatment. Indian Journal of Dermatology, Venereology, and Leprology. 2008 May $1 ; 74(3): 234$ https://doi.org/10.4103/0378-6323.41368

6) Modayil RR, Harugeri A, Parthasarathi G, Ramesh M, Prasad R, Naik V, Giriyapura V. Adverse drug reactions to antiretroviral therapy (ART): an experience of spontaneous reporting and intensive monitoring from ART centre in India. Pharmacoepidemiology and drug safety. 2010 Mar; 19(3):247-55. https://doi.org/10.1002/pds.1907

7) Mugisha JO, Donegan K, Fidler S, Ramjee G, Hodson A, Dunn DT, Porter K, Kaleebu P. Mean corpuscular volume as a marker for adherence to Zidovudine-containing therapy in HIV-infected adults. The open AIDS journal. 2012; 6:45. https://doi.org/10.2174/1874613601206010045

8) Sharma SK. Zidovudine-induced anaemia in HIV/AIDS. Indian Journal of Medical Research. 2010 0ct 1; 132(4):359-62.

9)https://accesspharmacy.mhmedical.com/content.aspx?sectionid=1460797 96\&bookid= 1861

10) Park K. Parks Textbook of Preventive in Social Medicine. Jabalpur: Banarsidas Bhanot Publishers; 2015; 357 - 359.

11) Consolidated guidelines on the use of antiretroviral drugs for treating and preventing HIV infections, June 2015; 98 - 100, Available at http://apps.who.int/medicinedocs/pdf/s4876e/s4876e.pdf.

12) Reddy, M. Y., Lokesh, A., Sivaranjani, V., Lakshmi, S. V. \& Subbaiah, M. V. Zidovudine Induced Hematological Disorders and Hyperpigmentation. World Journal of Pharmacy and Pharmaceutical Sciences, 2017; 6:1285-1290 